Andrews University

Digital Commons @ Andrews University

Faculty Publications

$9-2018$

\title{
Scholarly Publishing in Korea: Language, Perception, Practice of Korean University Faculty
}

\author{
Eun-Young Julia Kim \\ Andrews University, keun@andrews.edu
}

Follow this and additional works at: https://digitalcommons.andrews.edu/pubs

Part of the Bilingual, Multilingual, and Multicultural Education Commons, Communication Commons, Higher Education Commons, and the Korean Studies Commons

\section{Recommended Citation}

Kim, Eun-Young Julia, "Scholarly Publishing in Korea: Language, Perception, Practice of Korean University Faculty" (2018). Faculty Publications. 1032.

https://digitalcommons.andrews.edu/pubs/1032

This Article is brought to you for free and open access by Digital Commons @ Andrews University. It has been accepted for inclusion in Faculty Publications by an authorized administrator of Digital Commons @ Andrews University. For more information, please contact repository@andrews.edu. 


\title{
Scholarly Publishing in Korea: Language, Perception, Practice of Korean University Faculty
}

\section{Eun-Young Julia Kim ${ }^{1}$}

Published online: 21 September 2018

(c) Springer Science+Business Media, LLC, part of Springer Nature 2018

\begin{abstract}
This study reports how internationalization of academic knowledge is reflected in the language choice of Korean academic journals across disciplines and examines perceptions and practices of eighty two faculty from various disciplines at three Korean universities concerning publishing in English journals. The results indicate that natural science has the highest percentage of English-medium journals whereas those in humanities and social science predominantly use Korean as a medium of publication. Similar disciplinary patterns are observed in the responses to survey questions about frequency of publication as well as desire and preference for publishing papers in English. The biggest motivation for Korean scholars to publish in English was the desire to reach global scholarly communities. Implications of these findings are discussed.
\end{abstract}

Keywords Multilingual scholars · International journals $\cdot$ Academic writing · Korean academics

The recent decades have seen growing interest in examining perceptions and experiences of scholars in non-Anglophone countries concerning knowledge production and publication in English-medium journals. In the midst of the mounting pressure for those researchers outside the Anglophone countries to publish in English-medium journal, several scholars have argued for leveling the center and

Eun-Young Julia Kim

keun@andrews.edu

1 Department of English, Andrews University, 8975 Old 31, Berrien Springs, MI 49104, USA 
periphery ${ }^{1}$ in academic publishing to remove obstacles facing multilingual scholars as they try to disseminate their newly gained knowledge to the international academic communities. ${ }^{2}$

Critics have noted that the increased efforts on the part of international scholars to publish in center-based English journals largely reflect the corporatization of higher education, ${ }^{3}$ as academic institutions, in their pursuit of national and global academic reputation, grant high recognition and prestige to publications placed in elite English-medium journals. What truly motivates international scholars to choose to publish in English-medium journals, what challenges they face as they cope with the new demand, and how they overcome those challenges have been some of the received foci of previous studies. Findings of available studies paint a nuanced picture, as different circumstantial factors contribute to answering these questions.

In the context of Korea, the internationalization of higher education and the resultant English mandate have caused mounting pressure and intense competition among higher education institutions. Faculty promotion and tenure is based on a score-system in Korea. Moreover, research and publication, particularly those that appear in Science Citation Index (SCI), Social Science Citation Index (SSCI), or Arts and Humanities Citation Index (A\&HCI), receive higher scores on the faculty promotion and tenure as well as on the institutional rankings conducted by Joongan Ilbo and Chosun Ilbo, two national newspapers which publish university rankings each year. ${ }^{4}$ Since the predominant majority of journals indexed in these databases are based in the U.S. and Britain, increasingly more Korean scholars are encouraged to seek publications in internationally recognized English-medium journals. Also, some Korean academic journals are choosing English as a medium of publication.

Existing research surrounding this topic has examined multilingual scholars' perceptions and experiences in various contexts, but currently no existing study examines how internationalization is reshaping the language choice of academic journals across disciplines in Korea. Previous studies in the context of Korea have focused on

\footnotetext{
${ }^{1}$ Robert Phillipson, Linguistic imperialism. Oxford, U.K.: Oxford University Press, 1992, 52-53.

${ }^{2}$ See Diane Belcher, 'Seeking Acceptance in an English-only Research World'. Journal of Second Language Writing, 16 (2007): 1-22. 2007; Suresh Canagarajah, 'Nondiscursive Requirements in Academic Publishing, Material Resources of Periphery Scholars, and the Politics of Knowledge Production'. Written Communication, 13 (1996): 435-472; Suresh Canagarajah, 'Multilingual Writers and the Academic Community: Towards a Critical Relationship'. Journal of English for Academic Purposes, 1 (2000): 29-44; Gibson Ferguson, 'The Global Spread of English, Scientific Communication and ESP: Questions of Equity, Access, and Domain Loss'. Iberica, 13 (2007): 7-38.; John Flowerdew, 'Discourse Community, Legitimate Peripheral Participation, and the Nonnative-English-Speaking scholar'. TESOL Quarterly, 34 (2000): 127-150; John Swales, 'English as Tyrannosaurus Rex'. World Englishes, 16 (19970: 373-382.

3 Anssi Paasi, 'Globalization, Academic Capitalism, and the Uneven Geographies of International Journal Publishing Spaces'. Environment and Planning A, 37(2005): 769-789; Ingrid Piller and Jinhyun Cho, 'Neoliberalism and Language Policy'. Language in Society, 41 (2013): 23-44.

${ }^{4}$ Piller and Cho, 'Neoliberalism'.
} 
specific types of institutions such as top-tier universities or universities that specialize in a specific field. ${ }^{5}$

The present study seeks to contribute to the ongoing scholarly dialogue regarding issues surrounding global academic publishing for Korean scholars by expanding the scope through the data gathered from three mid-tier Korean universities to investigate how internationalization of academic knowledge is shown in the language choice of Korean academic journals across disciplines. It then reports perceptions and practices of 82 faculty from various disciplines concerning publishing in English journals.

\section{Review of Literature}

\section{Internationalization of Scholarly Publishing: Opportunities and Challenges of Periphery Scholars}

Existing studies that center on global academic publishing are typically framed around phenomena such as globalization and the ascendancy of English as a lingua franca in academic communication. Scholars have noted the disadvantages that nonnative English-speaking scholars experience in the knowledge production and publication for the global academic audience and expressed concerns about the hegemony of the center and the resultant power inequity. ${ }^{6}$ Previous studies observed that 'internationalization' is often associated with 'quality', and ability to write in English with being a 'good researcher'.

Some studies examined attitudes of so-called 'gate-keepers' toward papers submitted by nonnative English-speaking scholars. For instance, Flowerdew investigated attitudes and perceptions of English journal editors in an applied linguistics journal. ${ }^{9}$ The findings indicated that although the editors recognized the unique contribution of studies conducted by periphery scholars in several aspects such as theory verification and data triangulation, they found 'surface errors, parochialism,

\footnotetext{
5 See Dong Wan Cho, 'Science Journal Paper Writing in an EFL Context: The Case of Korea. English for Specific Purposes, 28 (2009): 230-239; Lee \& Lee, 'Publish (in International Indexed Journals) or Perish: Neoliberal ideology in a Korean University'. Language Policy, 12 (2013): 215-230; Sungwoo Kim and Michael Chesnut, 'Hidden Lessons for Developing Journals: A Case of North Americans Publishing in Korea. Journal of Scholarly Publishing, 47 (2016): 267-283.

${ }^{6}$ For example, Christine Pearson Casanave and Stephanie Vandrick, 'Writing for Scholarly pPublication: Behind the Scenes in Language Education. (Mahwah, NJ: Lawrence Erlbaum, 2003); John Flowerdew and Yongyan Li, 'The Globalization of Scholarship: Studying Chinese Scholars Writing for International Publication, in Writing in Foreign Language Contexts: Learning, Teaching, and Research, ed. Rosa M. Manchón (Bristol, UK: Multilingual Matters, 2009), 156-182; Sedef Uzuner-Smith, 'Multilingual Scholars' Participation in Core/Global Academic Communities: A Literature Review'. Journal of English for Academic Purposes, 7 (2008): 250-263.

7 Passi, 'Globalization, Academic Capitalism', 769.

8 Anna Olsson and Vera Sheridan, 'A Case Study of Swedish Scholars' Experiences with and Perceptions of the Use of English in Academic Publishing'. Written Communication, 29 (2012): 46.

9 John Flowerdew, 'Attitudes of Journal Editors to Nonnative Speaker Contributions'. TESOL Quarterly, 35 (2001): 121-150.
} 
absence of authorial voice, and nativized varieties of English' as problematic. ${ }^{10}$ In her study of recurring text features in the reviewers' comments for papers submitted to English for Specific Purposes by periphery scholars, Belcher found that while reviewers responded most positively to the topics chosen, a high percentage of negative comments concerned language use and style. ${ }^{11}$

Some scholars have commented on the implications of increased global publishing on the sustainability of local language. ${ }^{12}$ Curry and Lillis, in their ethnographic study of sixteen scholars in psychology in Slovakia, Hungary, and Spain, have examined how they negotiate their academic interests and showed that they write for multiple linguistic communities. ${ }^{13}$ Morley and Kerans pondered if language professionals such as translators and editors are contributing to the "demise of non-English academic discourse'. ${ }^{14}$

The findings from various studies show that each country and institution, coupled with individual scholars' own circumstances, either enhances or complicates the chances of publishing in English journals. The findings also indicate that generalizations made for 'periphery' scholars can be misleading as contexts in various countries present different opportunities and challenges. For instance, Duszak and Lewowicz, in their study of Polish scholars who seek to publish in English, identified several factors that seem to determine the outcome, such as the scholars' age, previous exposure to English, and their fields of study. ${ }^{15}$

Researchers have also noted that publication practices in social sciences in particular are 'heterogeneous and context-driven, ${ }^{16}$ and the language used in these fields relies heavily on 'nuance and refinements, which differ significantly among various national vernaculars, ${ }^{17}$ which can be a compounding factor for multilingual scholars' chances of publishing in English-medium journals.

\section{The Context of Korea}

According to the 2015 statistics from the United Nations Educational, Scientific and Cultural Organization (UNESCO), Korean scientific publications have almost doubled since 2005, overtaking those of similarly populated Spain. ${ }^{18}$ UNESCO reports

\footnotetext{
10 Flowerdew, 'Attitudes of Journal Editors', 121.

11 Belcher, 'Seeking acceptance', 1-22.

12 For example, Greg Morley and Mary Ellen Kerans, 'Bilingual Publication of Academic Journals: Motivations and Practicalities', in Supporting Research Writing: Roles and Challenges in Multilingual Settings, ed. Valerie Matarese (Witney, Oxford UK: Chandos Publishing, 2013), 121-14; Olsson and Sheridan, 'A Case Study of Swedish Scholars' Experiences'.

13 Mary Jane Curry and Theresa Lillis, 'Multilingual Scholars and the Imperative to Publish in English: Negotiating Interests, Demands, and Rewards'. TESOL Quarterly, 38 (2004): 663-688.

14 Curry and Lillis, 'Multilingual Scholars and the Imperatives', 122.

15 Duszak, A., Lewkowicz, J. (2008). Publishing academic texts in English: A Polish perspective. Journal of English for Academic Purposes, 7, 108-120.

16 Passi, 'Globalization, Academic Capitalism', 769.

17 Olsson and Sheridan, 'A Case Study of Swedish Scholars' Experiences', 46.

18 Unesco Science Report: Toward 2030, http://unesdoc.unesco.org/images/0023/002354/235406e.pdf. See also, Yongyan Zheng and Andy Xuesong Gao, 'Chinese Humanities and Social Science Schol-
} 
that between 2008 and 2014, the number of scientific articles catalogued in the Science Citation Index grew by $23 \%$, and growth was strongest among the upper middle-income economies, with the Republic of Korea dominating in engineering and physics.

To date, relatively a small number of studies have examined Korean scholars' experiences as available studies have mainly focused on Chinese, Japanese, Spanish, and European scholars. ${ }^{19}$ Existing research focusing on Korean scholars' motivations to publish in English-medium journals has shown that they are largely driven by external factors such as faculty assessment and tenure-promotion policies, which place a high premium on papers placed in English medium journals, more specifically, those that are indexed in SCI (Science Citation Indenx), SSCI (Social Science Citation Index), and A\&HCI (Arts and Humanities Citation Index). ${ }^{20}$ According to Piller and Cho, most of these journals are based in the U.S. and Britain, with journals based in Asian countries constituting less than one percent. ${ }^{21}$ Lee and Lee also identified institutional pressure and incentive as the biggest driving force that propels Korean scholars to publish in high-impact international journals. ${ }^{22}$ They further argued that the institutional demand is in essence interrelated with the aim to increase its reputation as a knowledge center. Similarly, Piller and Cho attribute this institutional mandate to 'academic capitalism and its attendant managerial culture' stemming from the ambition to achieve fame as a globally competitive institution. $^{23}$ 'Research and publication' is the most highly ranked criterion in the university rankings by two national newspapers. Joongang Ilbo, one of the two, for instance, assigns fifty five (out of 115) points to publications in journals indexed in those three indexes, and only fifteen points are allotted for publications published in domestic journals. $^{24}$

Cho reported that the linguistic aspect was the most problematic area for graduate students at Pohang University of Science and Technology as they try to publish in English-medium journals, whereas the majority of faculty at the university responded that language was not a major issue. ${ }^{25}$ Faculty from mathematics department, in particular, indicated that language was not a concern because writing in their field is limited to explications of theorems and equations. Although the language barrier is not deemed as the biggest obstacle, Cho reported that many Korean scholars rely on for-pay translation/editing services for preparing English manuscripts. It is not uncommon for faculty members to prepare their manuscripts

\footnotetext{
Footnote 18 (continued)

ars' Language choices in International Scholarly Publishing'. Journal of Scholarly Publishing, 48, no.1 (2016): 1-16, see especially p. 10.

19 See Uzuner-Smith, 'Multilingual Scholars' Participation', and Zheng and Gao, 'Chinese Humanities and Social Science Scholars' Language Choice'.

${ }^{20}$ Kim and Chesnut, 'Hidden Lessons for Developing Journals'.

21 Piller and Cho, 'Neoliberalism'.

${ }^{22}$ Lee and Lee, 'Publish (in International Indexed Journals) or Perish'.

23 Piller and Cho, 'Neoliberalism', 31.

24 Piller and Cho, 'Neoliberalism', 35.

${ }^{25}$ Cho, 'Science Journal Paper Writing in an EFL Context'.
} 
entirely in L1 and hire professional translators to translate their work to English. Currently, several academic editing services in Korea provide specialized translation/editing services for those who aim to publish in journals indexed in SCI, SSCI, and A\&HCI.

Scholars have also noted that the internationalization phenomenon is reshaping the local journals as some academic journals published in the periphery are choosing English as a medium of publication entirely or partially. ${ }^{26}$ According to the Korean Citation Index (KCI), which provides statistical information on Korean scholarly journals based on the academic disciplines and languages, a large percentage of Korean academic journals, especially in natural science, are currently published in English. However, no existing study has presented a comprehensive overview of the language usage in various Korean journals across disciplines. Surveying how the growing interest in disseminating research studies to a broader global academic community has affected, or is affecting, existing Korean academic journals in terms of language choice could provide further insights into the effect of internationalization on academic publishing.

The current study seeks to contribute to the ongoing scholarly discussion on multilingual scholars' global academic publishing by examining perceptions and experiences of Korean academics in three mid-tier universities as they try to increase visibility of their studies to the global audience. This paper focuses on the following questions:

1. What percentage of Korean academic journals use English as the language of medium?

2. What are the practices and perceptions of Korean academics concerning publishing in English? Are there any disciplinary differences?

\section{Method}

\section{Data Collection}

Data were collected from two different sources. To find out what percentage of journals published in Korea uses Korean and English as the medium of language and to see how they are distributed across disciplines, information was gathered from the Korean Citation Index (KCI) website, which provides up-to-date statistics on the number of Korean scholarly journals based on the fields, languages, and whether or not they are registered journals of the National Research Foundation of Korea (NRFK). Established in 2007 by NRFK, the main purpose of KCI is to provide indicators for the domestic research performance by analyzing citations in journals published by domestic academic entities.

\footnotetext{
${ }^{26}$ Françoise Salager-Meyer, 'Writing and Publishing in Peripheral Scholarly Journals: How to Enhance the Global Influence of Multilingual Scholars?' Journal of English for Academic Purposes, 13 (2014): 78-82.
} 
Answers to the second research question draw from a survey, which was prepared in Korean using Class Climate. The survey included questions concerning participants' perceptions and practices concerning publishing in English-medium journals. Participants were asked to identify their discipline before proceeding to the survey questions. (See "Appendix" for the survey in English).

A link to the survey was sent to the faculty teaching at three Korean universities via email. The three universities-Dankook University, Incheon National University, and Handong Global University-were randomly chosen. They are four-year universities not included among the top thirty universities in the 2016 Korean University Ranking presented by Joongang Ilbo and do not specialize in a specific field. By broadening the range of universities as data source, the current study sought to complement the findings from the previous studies, which have focused mostly on toptier universities or universities that specialize in a specific field. Participants' email addresses were obtained from the institutions' websites. A total of eighty seven faculty completed the survey. It included eleven faculty from humanities, thirty three from social science, thirty from engineering, eight from natural science, and five from Health. The data from the last group-health-however, was excluded from the second part of analysis (Research Question 2) due to the low response rate. Therefore, the final number of subjects used in the actual analysis is eighty two.

\section{Data Analysis}

Descriptive statistics and Analysis of Variance were used to measure means, standard deviations, and group differences. Chi square tests were performed to identify any potential patterns among answers. Two open ended questions were thematically analyzed using NVivo 11 in order to categorize different answers concerning reasons for or against publishing in English-medium journals.

\section{Results and Discussion}

Q1: What percentage of Korean academic journals use English as the language of medium?

The majority of Korean academic journals use Korean as a language of publication, but a closer look at the languages used in publication reveals some notable disciplinary differences. Journals in natural science have a higher percentage of English-medium journals whereas those in humanities and social science predominantly use Korean as a language of publication. Health and engineering also have more journals published in Korean, but the percentage of English journals are much higher than humanities and social science, although lower than natural science.

As of 2016, there are 5782 academic journals published in Korea. Among them, 1539 are registered at the NRFK. The registered status is given to those that meet 
certain quality criteria established by the Foundation. ${ }^{27}$ As Table 1 indicates, eighty nine percent of journals use Korean as a medium of language. Natural science has the fewest number of journals but has the highest percentage of English-medium journals, followed by health and engineering, and humanities and social science have a significantly low percentage of English-medium journals, although the number of journals published in these fields are the greatest (see Fig. 1).

An important footnote that should be added to this statistics is that currently, KCI does not specify which journals use English partially (i.e., on specific issues) or fully. For example, some journals in English language teaching include an "international issue," which uses English as a medium of language, while the rest of the issues are published in Korean. Since KCI does not specify the percentage of the English language use in each journal, the current study adopts general categories used by KCI-English or Korean. While considering` this categorization as absolute binaries could be misleading, the current information can serve a point of comparison for future researchers.

When we look at the distribution of journals that are indexed with NRFK, we find similar disciplinary patterns. That is, natural science, health, and engineering have more indexed journals, which satisfy the quality criteria established by the Foundation, that are published in English, whereas humanities and social science show the reverse pattern. In Korea, registered journals are given more weight in tenure and promotion evaluations and are considered more legitimate than non-registered journals, as the latter do not meet some of the National Research Foundation's criteria. The KCI indicates that journals in humanities and social science have much higher percentage of registered journals published in Korean. Conversely, more registered journals in natural science, engineering, and health are English-medium journals (see Fig. 2). Relatively lower numbers of Korean-medium journals in science could stem from the fact that tenure and policy evaluations for the sciences require SCI or SCIE journal publications far more than the other disciplines.

\section{Q2: What are the practices and perceptions of Korean academics concerning publishing in English?}

The first two survey items asked participants to indicate how frequently they publish their papers in English-medium journals and how much they desired to publish in English. Participants in natural science and engineering had a higher mean concerning the frequency in publishing in English-medium journals, compared to humanities and social science (see Table 2). Those from humanities in particular published significantly less in English. On the other hand, participants from all fields, including humanities, indicated a desire to publish in English, but the mean of natural science faculty was the highest. Faculty in natural science reported publishing more in English as well as higher desire to publish in English. In addition, they had a stronger desire to see more journals in their fields published in English,

\footnotetext{
27 This website describes how the foundation rates journals: https://www.nrf.re.kr/biz/info/info/ view?biz_no=8.
} 
Table 1 Journals published in Korean and English

\begin{tabular}{lllllll}
\hline & Humanities & Social Science & Engineering & Health & Natural Science & Total \\
\hline Korean & $1296(96 \%)$ & $1958(93 \%)$ & $1088(90 \%)$ & $519(73 \%)$ & $265(65 \%)$ & $5126(89 \%)$ \\
English & $60(4 \%)$ & $140(7 \%)$ & $126(10 \%)$ & $190(27 \%)$ & $140(35 \%)$ & $656(11 \%)$ \\
Total & 1356 & 2098 & 1214 & 709 & 405 & 5782 \\
\hline
\end{tabular}

The data was obtained in October 2016

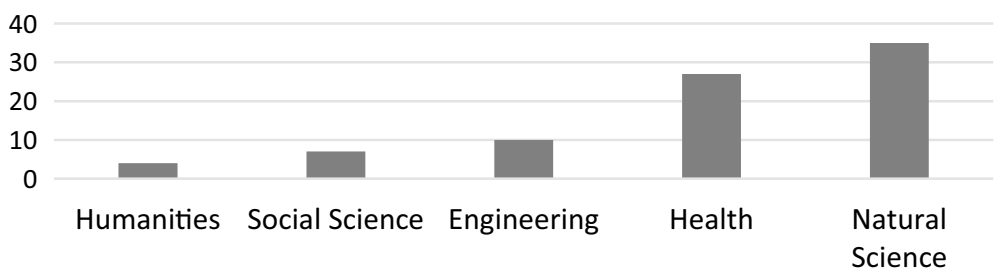

Percentage of English-medium Journals

Fig. 1 Percentage of English-medium journals

whereas the faculty in humanities and social science had the lowest frequency of publication and lower level of desire and preference. Standard deviations were also the smallest for responses from faculty in natural science and engineering and the highest for faculty in humanity for the two items concerning the frequency of publication and desire to publish in English-medium journals.

The next two survey items assessed participants' perceptions about how much they value publishing in English-medium journals and whether they want more Korean academic journals in their fields to be published in English. Overall, the majority of participants indicated that it is important to publish in English, although the importance was rated not as high by faculty in humanities. Faculty in natural science indicated the strongest preference for English-medium journals, while those in humanities indicated the lowest preference. Disciplinary differences for these four items were statistically significant at $p<.05$.

In response to the two open-ended questions concerning reasons why they do or do not publish in English-medium journals, a wide range of reasons were shared. For 'reasons for publishing in English-medium journals,' most comments fell into two major categories-a desire for a global scholarly exchange and a pressure from their universities. Out of seventy eight comments, forty five indicated a desire to engage with international scholars and to have their work objectively assessed by international scholars as the most important reason. Twenty six comments identified institutional demands as the most important reason for publishing in English-medium journals. Several participants wrote that their institutions gave higher scores in faculty performance evaluation for articles placed in English-medium journals, especially those indexed in SCI or SSCI.

Korean scholars in this study held mixed views concerning publishing in English-medium journals; while the majority recognized the value of having their 
(a)

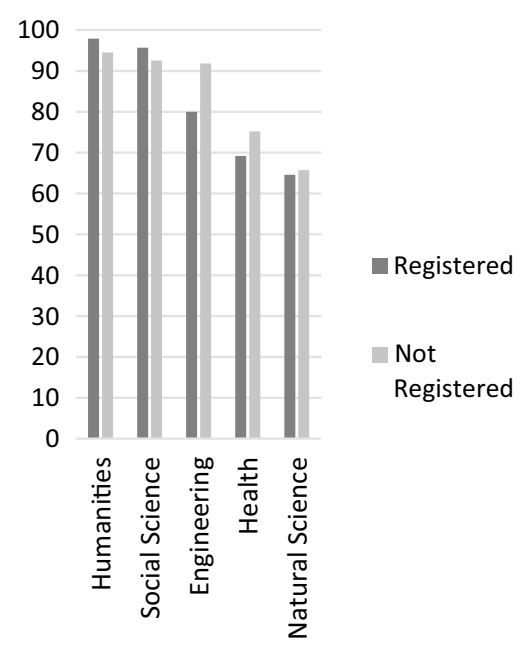

(b)

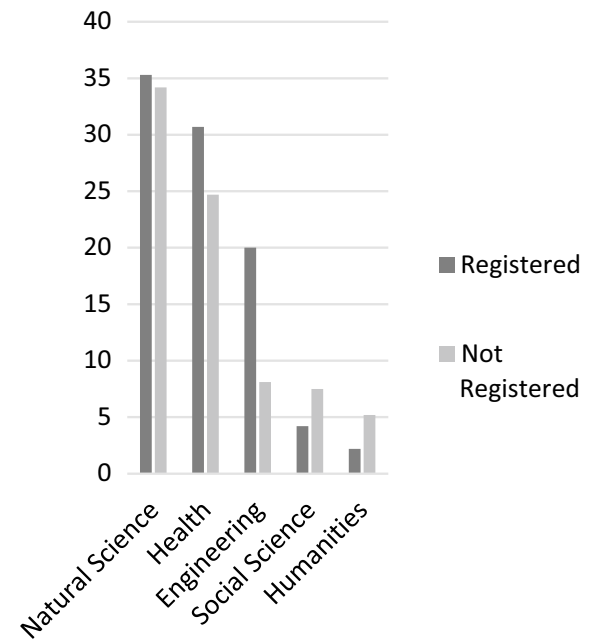

Fig. 2 Percentage of registered and un-registered among Korean-medium Journals (a) and Englishmedium journals (b)

Table 2 Perceptions and experiences

\begin{tabular}{|c|c|c|c|c|c|c|c|c|}
\hline \multirow[t]{2}{*}{ Fields } & \multicolumn{2}{|c|}{$\begin{array}{l}\text { Frequency of pub- } \\
\text { lishing in English } \\
(\mathrm{n}=81)\end{array}$} & \multicolumn{2}{|c|}{$\begin{array}{l}\text { Desire to publish } \\
\text { in English }(n=82)\end{array}$} & \multicolumn{2}{|c|}{$\begin{array}{l}\text { Importance of } \\
\text { publishing in } \\
\text { English }(n=81)\end{array}$} & \multicolumn{2}{|c|}{$\begin{array}{l}\text { Preference of } \\
\text { more English } \\
\text { journals in the } \\
\text { field }(n=81)\end{array}$} \\
\hline & $\mathrm{M}^{\mathrm{a}}$ & SD & $\mathrm{M}^{\mathrm{b}}$ & SD & $\mathrm{M}^{\mathrm{b}}$ & SD & $\mathrm{M}^{\mathrm{b}}$ & SD \\
\hline Humanities $(\mathrm{n}=11)$ & 1.7 & 1.0 & 3.7 & 1.2 & 3.2 & 1.3 & 2.3 & 1.3 \\
\hline Social Science $(n=33)$ & 2.5 & 1.0 & 4.2 & 0.7 & 3.9 & 0.8 & 3.4 & 1.0 \\
\hline Natural Science $(n=8)$ & 3.9 & 0.4 & 4.8 & 0.5 & 4.4 & 1.2 & 4.5 & 1.1 \\
\hline Engineering $(n=30)$ & 3.5 & 0.8 & 4.4 & 0.6 & 4.4 & 0.7 & 3.8 & 1.0 \\
\hline Total (82) & 2.9 & 1.1 & 4.3 & 0.8 & 4.0 & 0.9 & 3.5 & 1.2 \\
\hline
\end{tabular}

${ }^{a}$ The numbers on the scale correspond to 4: almost always; 3 : sometimes; 2 : seldom; 1: never

${ }^{\mathrm{b}}$ The numbers on the scale correspond to 5: strongly agree; 4: agree; 3: neutral; 2: disagree 1: strongly disagree

studies read and assessed by international scholars, some were resistant to publishing their studies in English-medium journals due to philosophical reasons, some of which are mentioned below. Only a small percentage of participants indicated that the cost involved in preparing manuscript in English through the help of professional editors was financially burdensome, and the majority of them reported that their institutions provide funding at least partly.

Also, a relatively small percentage of faculty identified language skills as an obstacle to publishing in English-medium journals. Unlike findings of recent studies 
of Spanish social scientists, ${ }^{28}$ for whom lack of English skills was the greatest obstacle in publishing research, not many faculty in the current study expressed lack of English skills as an impediment to publishing their studies in English-medium journals. Approximately half of the participants indicated having used the for-pay editing service at the level of proofreading, and approximately one fourth received help at the next level involving higher-order concerns. The fact that language difference was not a significant factor could be partly explained by the wide availability of forpay editors who specialize in academic publishing.

Concerning reasons for not publishing or not wanting to publish in Englishmedium journals, a total of fifty one comments were made. Although the comments were fewer than those in the previous question, the comments in this question had a greater variation. The most frequently mentioned demotivating factor was the time involved in the manuscript review and decision process. Eighteen participants mentioned that it took significantly more time to publish in English-medium journals, and several specifically mentioned the time involved in going through the review process before the final editor's decision is given. Twelve faculty indicated difficulties in composing in English. Ten indicated a negative attitude toward publishing in English due to philosophical reasons; they felt that publishing English is not, and should not, automatically be associated with higher quality. Several participants associated publishing in English-medium journals with lower quality, as demonstrated by predatory journals that are profit-oriented. Lastly, eight commented that they do not publish in English because they felt that their studies would not interest scholars outside Korea. They indicated that their fields of study focused on topics that are specific to Korea, such as ancient Korean history and Korean language and literature. It should be noted that their lack of incentive and motivation to publish in English could also stem from the fact that there is much less mandate from their institutions to publish in English-medium journals for tenure and promotion compared to faculty in science and engineering.

\section{Conclusion}

In this study, we have learned that despite the prevalent notion that periphery scholars' attempts to publish in English journals are mainly caused by external factors such as the institutional demand, the majority of participants in this study expressed a desire to share their research with the international audience and have their studies assessed by their global peers. Also interesting was the fact that language barrier was not perceived to be the greatest hindrance to publishing in English by the majority of participants. However, the current study draws from limited data pool, and the sample did not include all academic disciplines. Therefore, further research using samples from different contexts (e.g., different universities and

\footnotetext{
28 Maria-Lluïsa Gea-Valor, Jesús Rey-Rocha, and Ana I. Moreno, 'Publishing Research in the International Context: An Analysis of Spanish Scholars' Academic Writing Needs in the Social Sciences'. English for Specific Purposes, 36 (2014), 47-59.
} 
disciplines) would be needed to paint a more complete picture of the landscape of Korean scholarly publishing. Despite the limited scope, the author believes that the information presented in this paper will be useful to future researchers as it can provide point of comparison as they investigate the growth or decline of the use of English in Korean scholarly journals across disciplines.

Besides this practical purpose, the study raises some important issues. The current study indicates that Korean scholars continue to recognize the need for, as well as the value of, disseminating their research to the global academic community and having their studies assessed by their international peers. In reality, however, the gate keepers of highly regarded international journals which their institutions promote for tenure and promotion and on which the university rating is based in Korea are predominantly published in Anglophone countries. Besides, the kind of "global" scholars with whom the Korean scholars wish to engage are mainly scholars with strong English language skills affiliated with journals published in the so-called center. Equating the center scholars' validation as the necessary proof of quality check perpetuates the global academic hierarchies and increases the center-periphery dichotomy, rather than leveling it. To be sure, Englishization of academia in Korea would offer unique opportunities to the Korean scholarly community as publishing in English journals can help Korean scholars disseminate their studies to a wider audience. However, the higher premium currently placed on center-based indexes and upholding center scholars' assessment as proof of quality further increases center domination.

In addition, the increased usage of English as academic language by Korean scholars is likely to have a negative impact on the sustainability of Korean as an academic language. Although it would not be reasonable to speculate on the future of Korean as a scholarly language based on this one study, if English is recognized and adopted as the medium of scholarly communication by increasingly more Korean scholars, we cannot help but predict the demise Korean as academic language in the long run, especially in the fields of natural science, health, and engineering. The elevated status of English as a language of knowledge in these disciplines is likely to stunt the development of the Korean language as a language of scientific inquiry, lacking suitable Korean vocabulary to describe scientific phenomena. This can have ripple effects that are far-reaching, as the resultant non-use of the Korean language as scientific inquiry will create a language hierarchy, placing English at a higher position, furthering the domination of Anglophone center.

Scholarly debates on the ethical ramifications of English domination proliferated in the last several decades, and the discussions certainly increased awareness of various issues surrounding asymmetric flow of knowledge. They also led to some new measures taken by some journals in an effort to level the center and periphery by considering unique needs of scholars for whom English is not their first language. However, making real changes would not be possible unless the center-dependent subconsciousness entrenched in the academic institutions in the periphery is brought to the fore and recognized by members of their own community. 


\section{Appendix}

\section{Part I}

1. My field is
a. Humanities
b. Natural Science
c. Health
d. Social Science
e. Engineering
f. Other

2. I publish in English-medium journals in my field.
a. Almost always
b. Sometimes
c. Seldom
d. Never

3. I would prefer to publish in English-medium journals.
a. Strongly agree
b. Agree
c. Neutral
d. Disagree
e. Strongly disagree

4. I would like to see more journals in my field being published in English.
a. Strongly agree
b. Agree
c. Neutral
d. Disagree
e. Strongly disagree

5. I think it is important for scholars to publish their research in English-medium journals.
a. Strongly agree
b. Agree
c. Neutral
d. Disagree
e. Strongly disagree 
6. I try to publish in English-medium journals mainly because

7. I don't or haven't publish in English-medium journals mainly because

8. I use for-pay editing services when preparing my manuscript in English.
a. Almost always
b. Frequently
c. Sometimes
d. Seldom
e. Never

9. My institution helps with the cost of using for-pay editing services.
a. Yes
b. No

10. Paying for editing services is financially challenging for me.
a. Strongly agree
b. Agree
c. Neutral
d. Disagree
e. Strongly disagree

11. For-pay editing services have helped with my writing by (check all that apply)
a. Translating my paper into English
b. Proofreading for misspellings, punctuation, grammar, formatting, citations, and references.
c. Reorganizing the writing, tightening up the flow of argument, and rephrasing sentences for clarity and accuracy.
d. Making content-level changes by deleting, adding, and/or rewriting sentences to correct errors in ideas, reasoning, and explaining/applying theories.
e. Submitting my article to the journal and communicating with the journal editor on my behalf.

